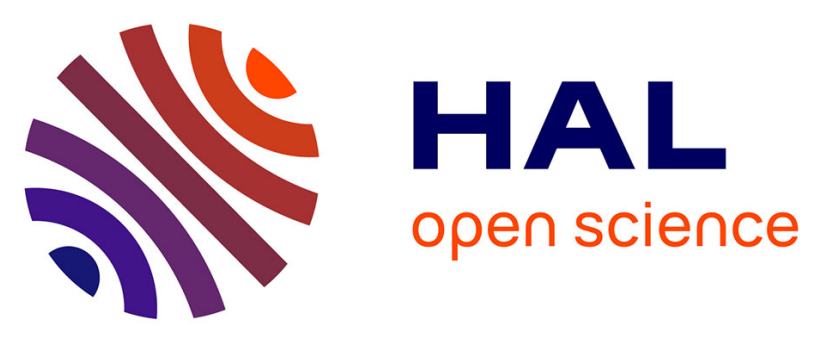

\title{
Run of homozygosity analysis reveals a novel nonsense variant of the CNGB1 gene involved in retinitis pigmentosa 45
}

\author{
Mélanie Fradin, Estelle Colin, Daniele Hannouche-Bared, Isabelle Audo, \\ José-Alain Sahel, Saskia Biskup, Wilfried Carre, Alban Ziegler, Christian \\ Wilhelm, Agnès Guichet, et al.
}

\section{To cite this version:}

Mélanie Fradin, Estelle Colin, Daniele Hannouche-Bared, Isabelle Audo, José-Alain Sahel, et al.. Run of homozygosity analysis reveals a novel nonsense variant of the CNGB1 gene involved in retinitis pigmentosa 45. Ophthalmic Genetics, 2016, 37 (3), pp.357-359. 10.3109/13816810.2015.1087578 . hal-01282329

\section{HAL Id: hal-01282329}

\section{https://hal-univ-rennes1.archives-ouvertes.fr/hal-01282329}

Submitted on 2 Mar 2017

HAL is a multi-disciplinary open access archive for the deposit and dissemination of scientific research documents, whether they are published or not. The documents may come from teaching and research institutions in France or abroad, or from public or private research centers.
L'archive ouverte pluridisciplinaire HAL, est destinée au dépôt et à la diffusion de documents scientifiques de niveau recherche, publiés ou non, émanant des établissements d'enseignement et de recherche français ou étrangers, des laboratoires publics ou privés. 


\section{Run of homozygosity analysis reveals a novel nonsense variant of the CNGB1 gene involved in retinitis pigmentosa 45}

Mélanie Fradina, Estelle Colin ${ }^{b}$, Daniele Hannouche-Bared ${ }^{c}$, Isabelle Audo ${ }^{d}$, Jose Alain Saheld, Saskia Biskup ${ }^{e}$, Wilfried Carréf, Alban Ziegler ${ }^{\mathrm{b}}$, Christian Wilhelme, Agnès Guichet ${ }^{\mathrm{b}}$, Sylvie Odent ${ }^{\mathrm{a}, \mathrm{g}}$, and Dominique Bonneau ${ }^{\mathrm{b}, \mathrm{h}}$

aservice de Génétique Clinique, Centre de référence CLAD-Ouest, CHU Rennes, Rennes, France; bService de Génétique, CLAD-Ouest, CHU d'Angers, Angers, France; 'Clinique Ophtalmologique Saint Laurent, Rennes, France; 'INSERM U968, CNRS UMR_7210, Université Pierre et Marie Curie, Paris 06, UMR_S 968, Département de Génétique, Institut de la Vision, Centre Hospitalier National d'Ophtalmologie des Quinze-Vingts, INSERM-DHOSCIC 503, Paris, France; 'CEGAT, Tübingen, Germany; 'taboratoire de Génétique Moléculaire et Génomique, CHU Pontchaillou, Rennes, France; gUniversité de Rennes 1, CNRS UMR 6290, Rennes, France; 'UMR CNRS 6214 - INSERM 1083, Université d'Angers, Angers, France

Retinitis pigmentosa (RP), a clinically and genetically heterogeneous retinal disease, entails abnormalities of the rod and cone photoreceptors or the retinal pigment epithelium, leading to progressive visual loss (1). Since RP predominantly affects the rods, the visual impairment is usually manifested as night blindness and progressive loss of the visual field. The cones are usually affected at a later stage, allowing preservation of the patient's daytime vision for several years or even decades (1). More than 50 different genes or loci are involved in cases of non-syndromic RP (2). One of these, CNGB1, a gene encoding the beta-subunit of the cGMP-gated channel of the rods, is involved in an autosomal recessive form of nonsyndromic RP (RP45, MIM 613767). Here, we present the first case of RP45 caused by an unequivocal homozygous nonsense variant of CNGB1 identified by run of homozygosity $(\mathrm{ROH})$ analysis. In addition, we review the pathogenic variants of CNGB1 as reported to date (Table 1) (3-13).

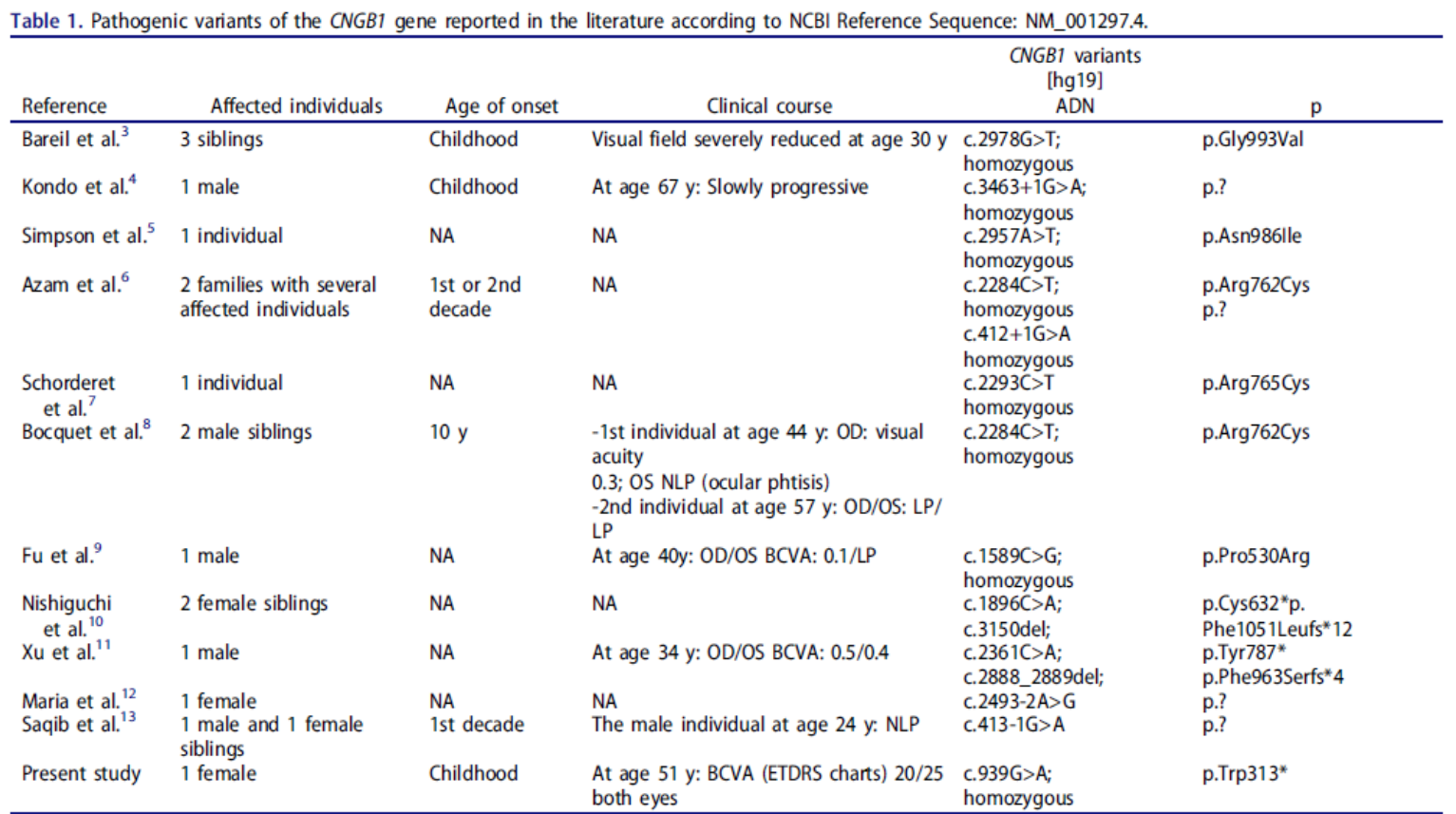

BCVA, best corrected visual acuity (on the Snellen decimal scale if not otherwise specified); OD, right eye; OS, left eye; LP, light perception; NLP, no light perception; $y$, year; NA, not available 
Table 1. Pathogenic variants of the CNGB1 gene reported in the literature according to NCBI Reference Sequence: NM_001297.4.

The pedigree of the family of French origin is shown in Figure 1. The family history revealed the consanguineous marriage of the parents $(f=1 / 32)$ but there was no history of RP.

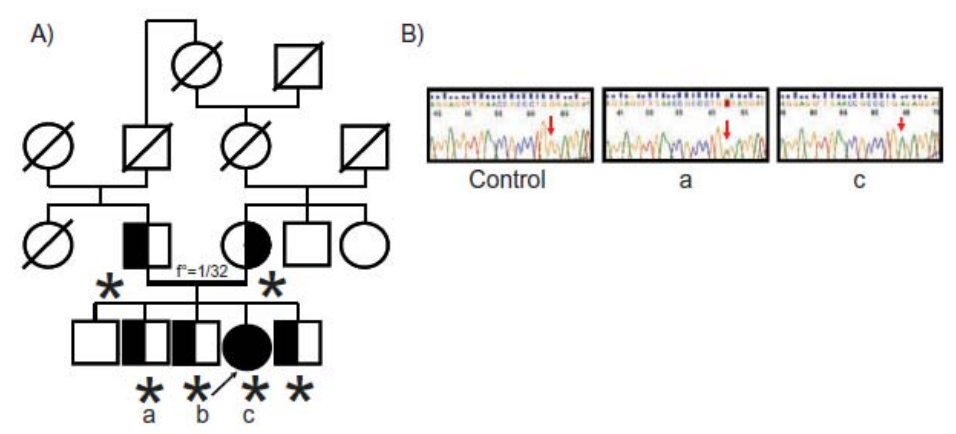

Figure 1. (A) Pedigree of the family showing the consanguinity loop. The arrow indicates the proband, and the asterisks indicate the individuals for whom DNA was available. Half-filled circles and squares represent heterozygous individuals, filled circle the homozygous proband. (B) DNA sequence of CNGB1 (GenBank NM_001297.4, NC_000016.9) from an unaffected brother (a) and from the affected index case (c).

The affected individual was a 51-year-old female who had complained of disturbances in night vision since early childhood. RP, diagnosed at age 23 , had led to severe constriction of the visual field by age 45 . She had no other medical history and, in particular, no olfactory impairment. She had undergone cataract surgery at age 50 with significant visual improvement. The best corrected visual acuity, assessed using the ETDRS chart, was 20/25 in both eyes, with optical correction of plano $(-50) 30^{\circ}$ in the right eye and $+0.25(-1.50) 175^{\circ}$ in the left eye. Fundus examination revealed a waxy pallor of the optic discs, slightly narrowed retinal vessels, and pigmentary changes in the fundus periphery, which relatively spared the macular region (Figure 2A). Fundus autofluorescence showed a high density perimacular ring characteristic of RP (Figure 2B). The macular function was preserved as confirmed by spectral domain optical coherence tomography, which showed normal macular structure (Figure 2C). The visual field was constricted in both eyes and the binocular kinetic visual field, using the III4e stimulus, was reduced to the central $10^{\circ}$. The full-field electroretinogram, performed according to the ISCEV standard, did not reveal any detectable response. 


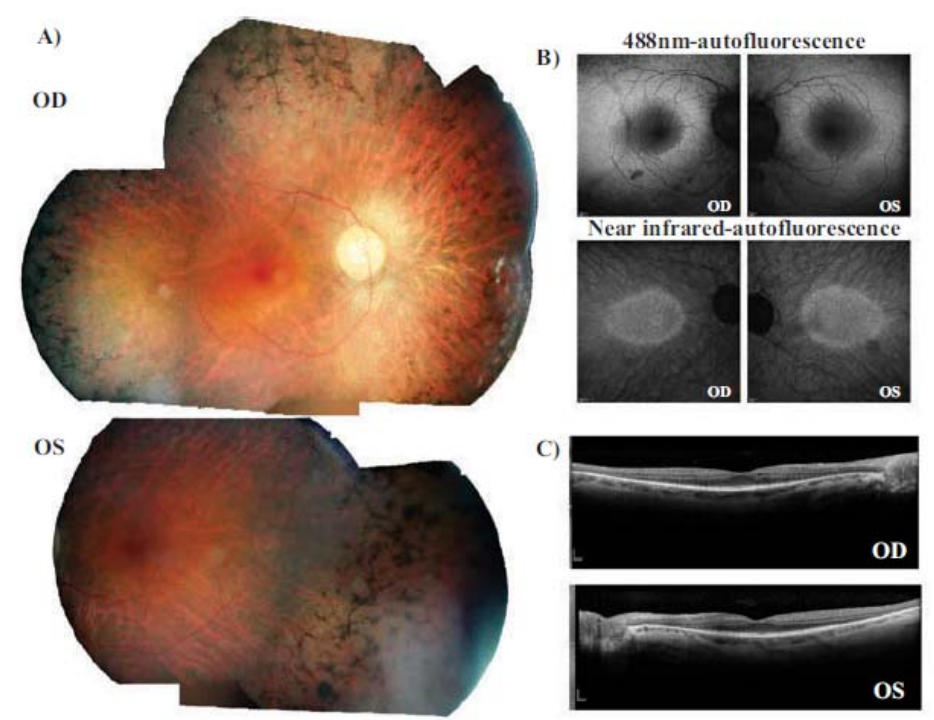

Figure 2. Fundus examination of the proband. (A) Fundus of the right (Ocula Dextra, OD) and left (Ocula Sinistra, OS) eyes showing typical features of rod-cone dystrophy including pigmentary changes in the peripheral retina with preservation of the macular area, narrowing of retinal blood vessels and waxy disc pallor, (B) Fundus autofluorescence at $488 \mathrm{~nm}$ and in near infrared revealing patchy loss of autofluorescence outside the vascular arcade and a perifoveal ring of hyperautofluorescence with macular preservation; and (C) Spectral Domain Optical Coherence tomography horizontal scan showing the normal foveal lamination.

DNA samples were obtained from the proband and two of her unaffected brothers. Informed consent was obtained from all participants prior to their participation in this study.

$\mathrm{ROH}$ analysis was performed using an Infinium HumanCytoSNP-12v2H array (Illumina, San Diego, CA, USA) containing 220,000 single nucleotide polymorphisms (SNPs) with an average spacing of $30 \mathrm{~kb}$. The results were interpreted using the Illumina GenomeStudio software v2011.1 and the Copy Number Variation partition v3.1.6. The CNGB1 gene sequence was analyzed using PCR and subsequent direct bidirectional sequencing of the coding regions (GenBank NM_001297.4, NC_000016.9) and the flanking intronic regions.

Analysis of the SNP array revealed that $10 \mathrm{ROHs}(43 \mathrm{Mb})$ were present in the affected individual but absent in both unaffected brothers. The largest $\mathrm{ROH}$ was a $24 \mathrm{Mb}$ interval in chromosome 16q12.1q23 (52,325,676-76,532,392). This ROH contained 595 genes including 176 OMIM genes among which only CNGB1 was known to be involved in RP. Subsequent Sanger sequencing of CNGB1 showed that the proband was homozygous for the nonsense variant c.939G $>$ A; p.Trp313*. Her healthy parents as well as two of her healthy brothers were heterozygous for this variant, which was not found in 120 ethnically matched control chromosomes (Figure 1). Although variant softwares are inappropriate for analyzing the consequences of nonsense mutations, an evaluation using the Alamut software predicts that the RNA containing c.939G $>$ A encodes for a truncated protein deprived of all its functional domains. Moreover, this variant is referenced neither in the Single Nucleotide Polymorphism database nor in the Exome Aggregation Consortium database. Nonetheless, it is of note that a fairly similar variant of CNGB1, namely c. $952 \mathrm{C}>\mathrm{T}$; p.Gln $318^{*}$, has been referenced as pathogenic in the ClinVar database (www.ncbi.nlm.nih.gov/clinvar/).

The involvement of CNGB1 in RP was first reported in 2001 using homozygosity mapping to identify a homozygous variant (c.2978G $>$ T) in three siblings affected with non-syndromic RP (3). To date, only 13 pathogenic CNGB1 variants have been reported in 12 families (Table 1) (3-13). Although clinical details are lacking in some reports and the methods used for evaluating visual impairment differ from one publication to another, it appears that RP45 has 
an early onset with a rather slow progression (4), but no genotype-phenotype correlation has been established thus far.

RPs are highly heterogeneous genetic conditions with mutations in more than 50 different genes or loci, making the delineation of the underlying molecular defect challenging for both patient and clinician. Indeed, establishing a molecular diagnosis is a prerequisite to preventive measures such as genetic counseling, prenatal diagnosis, and preimplantation diagnosis. Moreover, in the near future, the precise determination of the molecular defect responsible for $\mathrm{RP}$ will be of major importance in determining the eligibility of patients for clinical gene therapy trials relevant to their specific mutations.

Finally, this study shows that $\mathrm{ROH}$ analysis is a clinically relevant tool for performing a genotype-first identification of recessive genes responsible for RP.

\section{Acknowledgements}

The authors are grateful to the patient and her family, to Kanaya Malkani for critical reading of this work, and to the technicians of our laboratory for their competence.

\section{Declaration of interest}

The authors report no conflicts of interest. The authors alone are responsible for the content and writing of this article.

\section{References}

1. Fahim AT, Daiger SP, Weleber RG. Retinitis pigmentosa overview. 2000 Aug 4 [Updated 2013 Mar 21]. In: Pagon RA, Adam MP, Ardinger HH, et al., editors. GeneReviews ${ }^{\circledR}$

[Internet]. Seattle (WA): University of Washington, Seattle; 1993-2015. Available from: http://www.ncbi.nlm.nih.gov/ books/NBK1417/

2. Daiger SP, Sullivan LS, Bowne SJ. Genes and mutations causing retinitis pigmentosa. Clin Genet 2013;84:132-141.

3. Bareil C, Hamel CP, Delague V, et al. Segregation of a mutation in CNGB1 encoding the beta-subunit of the rod cGMP-gated channel in a family with autosomal recessive retinitis pigmentosa.

Hum Genet 2001;108:328-334.

4. Kondo H, Qin M, Mizota A, et al. A homozygosity-based search for mutations in patients with autosomal recessive retinitis pigmentosa, using microsatellite markers. Invest Ophthalmol Vis Sci 2004;45:4433-4439.

5. Simpson DA, Clark GR, Alexander S, et al. Molecular diagnosis for heterogeneous genetic diseases with targeted high-throughput DNA sequencing applied to retinitis pigmentosa. J Med Genet 2011;48:145-151.

6. Azam M, Collin RW, Malik A, et al. Identification of novel mutations in Pakistani families with autosomal recessive retinitis pigmentosa. Arch Ophthalmol 2011;129:1377-1378. 
7. Schorderet DF, Iouranova A, Favez T, et al. IROme, a new highthroughput molecular tool for the diagnosis of inherited retinal

dystrophies. Biomed Res Int 2013;2013:198089.

8. Bocquet B, Marzouka NA, Hebrard M, et al. Homozygosity mapping in autosomal recessive retinitis pigmentosa families detects novel mutations. Mol Vis 2013;19:2487-2500.

9. Fu Q, Wang F, Wang H, et al. Next-generation sequencing-based molecular diagnosis of a Chinese patient cohort with autosomal recessive retinitis pigmentosa. Invest Ophthalmol Vis Sci

2013;54:4158-4166.

10. Nishiguchi KM, Tearle RG, Liu YP, et al. Whole genome sequencing in patients with retinitis pigmentosa reveals pathogenic DNA structural changes and NEK2 as a new disease gene. Proc Natl Acad Sci U S A 2013;110:16139-16144.

11. Xu Y, Guan L, Shen T, et al. Mutations of 60 known causative genes in 157 families with retinitis pigmentosa based on exome sequencing. Hum Genet 2014;133:1255-1271.

12. Maria M, Ajmal M, Azam M, et al. Homozygosity mapping and targeted sanger sequencing reveal genetic defects underlying inherited retinal disease in families from Pakistan. PLoS One 2015;10:e0119806. 13. Saqib MA, Nikopoulos K, Ullah E, et al. Homozygosity mapping reveals novel and known mutations in Pakistani families with inherited retinal dystrophies. Sci Rep 2015;5:9965. 